\title{
A Meta-analysis Comparing Lateral Decubitus with Supine Position for Surgery for Intertrochanteric Fractures
}

Fuqian Liu, Han Xie, Weiguo Liang*, Dongping Ye and Yicun Yao

Guangzhou Red Cross Hospital, The Fourth Affiliated Hospital of Jinan University, Tong Fu Zhong Rd, Guangzhou, China

\begin{abstract}
Purpose: There are few studies compares surgery with proximal femoral nail antirotation (PFNA) in lateral decubitus with that in supine position about their advantages and disadvantages for patients with intertrochanteric femoral fractures. Previous studies reported conflicting findings. This meta-analysis was to compare the efficacy and safety of surgery with PFNA in different surgical positions.

Methods: Relevant randomized controlled trials comparing surgery with PFNA in lateral decubitus with surgery in supine position for intertrochanteric fractures patients were included into this meta-analysis. Inclusion criteria of this meta-analysis were: randomized controlled trials comparing lateral decubitus with supine position for surgery for intertrochanteric fractures and reporting at least one of the main outcomes, including blood loss, operating time, hospital stay, and length of incision, Harris values and union time.

Results: Six randomized controlled trials were finally included into this meta-analysis. Pooled results showed that there were less blood loss, less operation time, smaller incision and higher Harris values score in lateral decubitus group. Sensitivity analysis by sequential omission of individual studies showed the significance of weighted mean
\end{abstract} difference was robust, which suggested this outcome was credible.

Conclusions: Surgery with PFNA in lateral decubitus can benefit intertrochanteric fractures patients with less blood loss, less operation time, shorter incision and high Harris values scores compared with surgery in supine position according to our research.

Keywords: Intertrochanteric femoral fracture; Proximal femoral nail antirotation; Lateral decubitus; Supine position; Meta-analysis

\section{Introduction}

Intertrochanteric femoral fracture has become increasingly common especially in elderly patients $[1,2]$. Treatment of intertrochanteric femoral fracture depends on medical condition, bone quality and biomechanics of the fracture configuration of the patient [2,3]. In the past few decades, Intertrochanteric Femoral Fractures could be treated by using several effective internal fixation such as dynamic hip screw (DHS), dynamic condylar screws (DCS), proximal femoral nail (PFN) and proximal femoral nail antirotation (PFNA). Among these internal fixations, proximal femoral nail antirotation shows its advantages compared with other internal fixations [4-6]. Surgery with PFNA can benefit patients with intertrochanteric femoral fracture with less blood loss, less operation time, fewer complications. In result, PFNA is used globally.

Proximal femoral nail antirotation is generally used in surgery with supine position. This surgery has a high require of operating bed and equipment of fluoroscopy, which limits it being used in more primary hospitals. Recently, more and more surgeons perform surgery with PFNA in lateral decubitus. Surgery with PFNA in lateral decubitus doesn't need an extension table, so it can be performed in primary hospitals. Additionally, some surgeons observe that surgery in lateral decubitus has some advantages, such as less blood less, less operation time, comparing with surgery in supine position. However, there are not so many studies compares surgery in lateral decubitus with that in supine position about their advantages and disadvantages. Thus, to provide the most comprehensive assessment of the lateral decubitus and supine position for surgery for intertrochanteric fractures, we performed this metaanalysis based on all relevant randomized controlled trials comparing lateral decubitus with supine position for surgery for intertrochanteric fractures.

\section{Methods}

\section{Search strategy and eligibility criteria}

We searched Pubmed, Embase, and China Knowledge Infrastructure (CNKI) databases for randomized controlled trials comparing lateral decubitus with supine position for surgery for intertrochanteric fractures. We used the following search iterms: ("PFNA" or "proximal femoral nail antirotation") and ((“surgical position”) or (("lateral decubitus") and ("supine position"))) and ("intertrochanteric fractures" or "peritrochanteric fractures" or "subtrochanteric fractures" or "pertrochanteric fractures" or "extracapsular hip fractures"). The references of the retrieved articles were also confirmed and language restriction wasn't imposed in our search.

Inclusion criteria of this meta-analysis were: randomized controlled trials comparing lateral decubitus with supine position for surgery for intertrochanteric fractures and reporting at least one of the main outcomes, including blood loss, operating time, hospital stay, and length of incision, Harris values and union time. Exclusion criteria were: cases series that investigated either lateral decubitus or supine position for surgery for intertrochanteric fractures, data were

*Corresponding author: Weiguo Liang, Guangzhou Red Cross Hospital, The Fourth Affiliated Hospital of Jinan University, 396\# Tong Fu Zhong Rd. Guangzhou 510220, China, Tel: +86 15017541886; E-mail: liangweiguo193@163.com

Received May 20, 2016; Accepted July 05, 2016; Published July 18, 2016

Citation: Liu F, Xie H, Liang W, Ye D, Yao Y (2016) A Meta-analysis Comparing Lateral Decubitus with Supine Position for Surgery for Intertrochanteric Fractures. J Arthritis 5: 211. doi: 10.4172/2167-7921.1000211

Copyright: () 2016 Liu F, et al. This is an open-access article distributed under the terms of the Creative Commons Attribution License, which permits unrestricted use, distribution, and reproduction in any medium, provided the original author and source are credited. 
duplicated, demographic background of the patients and preoperative conditions were not similar, usable data were not reported and inconsistencies were resolved by reaching a consensus between all authors after discussion.

\section{Data extraction and quality assessment}

We extracted following information from every study: Year of publication, study design, number of patients, fracture classification, average follow-up time, blood loss, operating time, hospital stay, length of incision, Harris values and union time. Quality of randomized controlled trials included in this meta-analysis was assessed by the Jadad score [7], which was as follows: was the study described as randomized, was the study described as double blind, was there a description of withdrawals and dropouts [7]. Randomized controlled trails with scores no less than three points were defined as high quality, while with scores less than three points were defined as lesser quality randomized controlled trails [7].

\section{Statistical analysis}

In each study the pooled odds ratio (OR) with a $95 \%$ confidence interval (CI) was calculated for dichotomous outcomes, and weighted mean difference (WMD) with a 95\% confidence interval (CI) was calculated for continuous outcomes. To assess the betweenstudy heterogeneity more precisely, both the $\mathrm{Chi}^{2}$ based $\mathrm{Q}$ statistic test (Cochran's Q statistic [8]) to test for heterogeneity and the $I^{2}$ statistic to quantify the proportion of the total variation attributable to heterogeneity were calculated [9]. A significance level of less than 0.10 for the $\mathrm{Chi}^{2}$ test was interpreted as evidence of heterogeneity. When there was no statistical evidence of heterogeneity, a fixed effect model was adopted [10]; otherwise, a random effect model was chosen [11]. Besides, to validate the credibility of outcomes in this metaanalysis, a sensitivity analysis was performed by sequential omission of individual studies [12]. Publication bias was investigated by funnel plot and an asymmetric plot suggested possible publication bias [13] Statistical analyses were performed with the software program RevMan (Version 5.0, Copenhagen: The Nordic Cochrane Centre, the Cochrane Collaboration). All P-values were two-sided and a P-value of less than 0.05 was deemed statistically significant.

\section{Results}

\section{Study characteristics}

There were 67 initial record identified. A total of 57 of these records were excluded, leaving 10 potentially relevant studies. Then we excluded 2 non-random studies and 2 studies for no available data. Six randomized controlled trials were included into this meta-analysis [14-19]. Table 1 summarized the main characteristics of the included studies. Table 2 showed the methodological quality of included studies in this meta-analysis. The quality of randomized controlled trials included was assessed using the Jadad scoring system, and three trials were high quality randomized controlled trials with scores no less than three points (Figure 1).

\section{Blood loss and operation time}

Data for blood loss were reported in 6 trials (Table 3 and Figure $2)$. There was significant heterogeneity among these trials $\left(I^{2}=95 \%\right.$, $\mathrm{P}<0.00001)$. The random effects model was used to pool the results. It was showed in this meta-analysis that surgery in lateral decubitus was marginally associated with less blood loss compared with surgery in supine position $\left(\mathrm{WMD}_{\text {Blood loss }}=-52.12 \mathrm{ml}, 95 \% \mathrm{CI}-87.61\right.$ to -16.63 , $\mathrm{P}=0.004$ ) (Figure 2). Besides, sensitivity analysis by sequential omission of individual studies showed the significance of $\mathrm{WMD}_{\text {Blood loss }}$ was robust, which suggested this outcome was credible.

Data for operation time were reported in 5 trials (Table 3 and Figure 2). There was no significant heterogeneity among these trials $\left(\mathrm{I}^{2}=0 \%, \mathrm{P}=0.66\right)$. The fixed effects model was used to pool the results. It was showed in this meta-analysis that surgery in lateral decubitus was marginally associated with less operation time compared with surgery in supine position $\left(\mathrm{WMD}_{\text {Operation time }}=-14.77 \mathrm{~min}, 95 \% \mathrm{CI}-16.55\right.$ to $-12.99, \mathrm{P}<0.00001$ ) (Figure 2 ). Besides, sensitivity analysis by sequential omission of individual studies showed the significance of WMD time was robust, which suggested this outcome was credible.

\section{Length of incision}

Data for length of incision were reported in 3 trials (Table 3 and Figure 3). There was no significant heterogeneity among these trials $\left(\mathrm{I}^{2}=24 \%, \mathrm{P}=0.27\right)$. The fixed effects model was used to pool the results.

\begin{tabular}{|c|c|c|c|c|}
\hline Study & Study design ${ }^{a}$ & Indication & lateral decubitus group & Supine position group \\
\hline Li Xue et al. [14] & $\mathrm{RCT}$ & intertrochanteric fractures (31A1-3) & 60 patients ( 77.3 years, 26 males) & 60 patients ( 75.7 years, 29 males) \\
\hline Zhu Weiguo et al. [15] & $\mathrm{RCT}$ & intertrochanteric fractures (31A1-3) & 40 patients ( 76.5 years, 17 males) & 40 patients ( 78.3 years, 19 males) \\
\hline Liu Jianmin et al. [16] & $\mathrm{RCT}$ & intertrochanteric fractures (31A1-3) & 22 patients ( 70.3 years, 13 males) & 21 patients ( 71.1 years, 12 males) \\
\hline Fu Yuping et al. [17] & $\mathrm{RCT}$ & intertrochanteric fractures (Evans II-IV) & 22 patients & 20 patients \\
\hline Huang Jin et al. [18] & $\mathrm{RCT}$ & intertrochanteric fractures & 48 patients & 31 patients \\
\hline Yang bo et al. [19] & $\mathrm{RCT}$ & intertrochanteric fractures (Evans I-IV) & 17 patients & 14 patients \\
\hline
\end{tabular}

Table 1: Man characteristics of the studies included into the meta-analysis.

\begin{tabular}{|c|c|c|c|c|c|c|c|c|}
\hline \multirow[t]{2}{*}{ Study } & \multirow[t]{2}{*}{ Randomization } & \multirow[t]{2}{*}{$\begin{array}{c}\text { Allocation } \\
\text { concealment }\end{array}$} & \multirow[t]{2}{*}{ Blinding } & \multirow[t]{2}{*}{$\begin{array}{l}\text { Loss to } \\
\text { follow-up }\end{array}$} & \multirow[t]{2}{*}{$\begin{array}{l}\text { Jadad } \\
\text { score }\end{array}$} & \multicolumn{3}{|c|}{ Baseline } \\
\hline & & & & & & Age & Gender & Fracture type \\
\hline Li Xue et al. [14] & Adequate & Unclear & Unclear & Yes & 4 & Comparable & Comparable & Comparable \\
\hline Zhu Weiguo et al. [15] & Adequate & Unclear & Unclear & Yes & 4 & Comparable & Comparable & Comparable \\
\hline Liu Jianmin et al. [16] & Adequate & Unclear & Unclear & Yes & 4 & Comparable & Comparable & Comparable \\
\hline Fu Yuping et al. [17] & Inadequate & Unclear & Unclear & Yes & 2 & Comparable & Comparable & Comparable \\
\hline Huang Jin et al. [18] & Inadequate & Unclear & Unclear & Yes & 3 & Comparable & Comparable & Comparable \\
\hline Yang bo et al. [19] & Adequate & Unclear & Unclear & Yes & 3 & Comparable & Comparable & Comparable \\
\hline
\end{tabular}

Table 2: Methodological quality of included studies in this meta-analysis. 
Citation: Liu F, Xie H, Liang W, Ye D, Yao Y (2016) A Meta-analysis Comparing Lateral Decubitus with Supine Position for Surgery for Intertrochanteric Fractures. J Arthritis 5: 211. doi: 10.4172/2167-7921.1000211

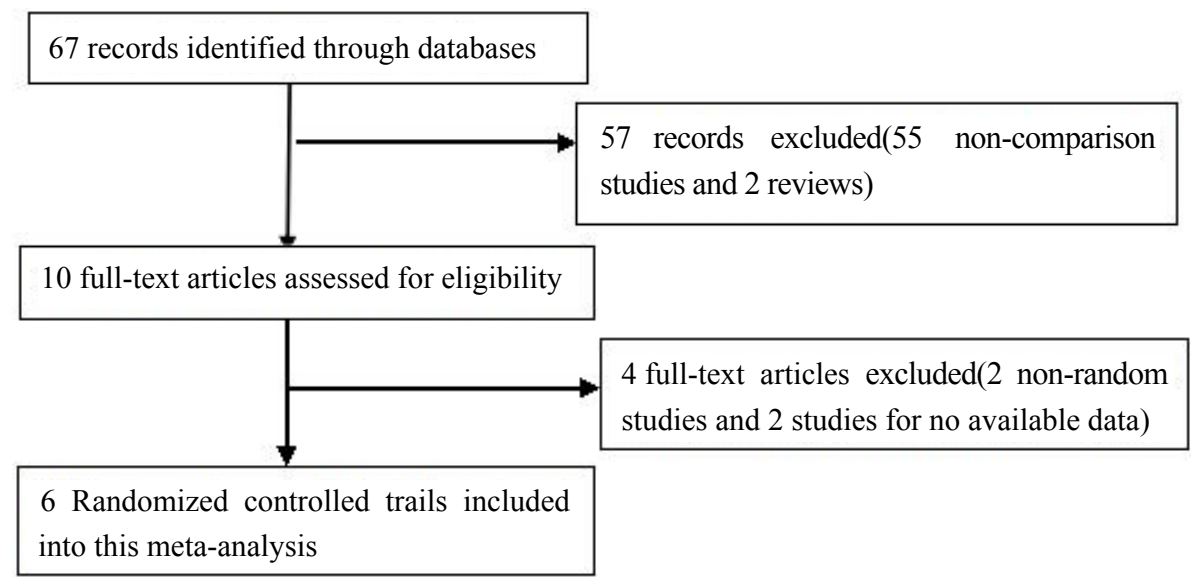

Figure 1: Flow chart demonstrating selection of studies for inclusion in the meta-analysis.

\begin{tabular}{|c|c|c|c|c|c|c|}
\hline \multirow{2}{*}{ Comparison items } & \multirow{2}{*}{$\begin{array}{c}\text { Number of included } \\
\text { studies }\end{array}$} & \multicolumn{2}{|c|}{ WMD or odds ratio } & \multicolumn{2}{|c|}{ Heterogeneity } & \multirow{2}{*}{ Model } \\
\hline & & WMD/OR(95\%Cl) & P-value & $I^{2}(\%)$ & $\mathbf{P}_{\mathrm{H}}$ & \\
\hline Blood loss & 6 & $-52.12(-87.61$ to -16.63$)$ & 0.004 & 95 & $<0.00001$ & Random \\
\hline Operation time & 5 & $-14.77(-16.55$ to -12.99$)$ & $<0.00001$ & 0 & 0.66 & Fixed \\
\hline Hospital stay & 3 & $-0.89(-2.34$ to -0.55$)$ & 0.23 & 79 & 0.009 & Random \\
\hline Length of incision & 3 & $-2.47(-2.64$ to -2.30$)$ & $<0.00001$ & 24 & 0.27 & Fixed \\
\hline Harris values & 3 & 1.36 (0.01 to 2.70$)$ & 0.05 & 0 & 0.83 & Fixed \\
\hline Union time & 4 & $-1.00(-3.20$ to -1.19$)$ & 0.37 & 94 & $<0.00001$ & Random \\
\hline
\end{tabular}

Table 3: Summary of meta-analysis of comparing lateral decubitus with supine position for surgery for intertrochanteric fractures.

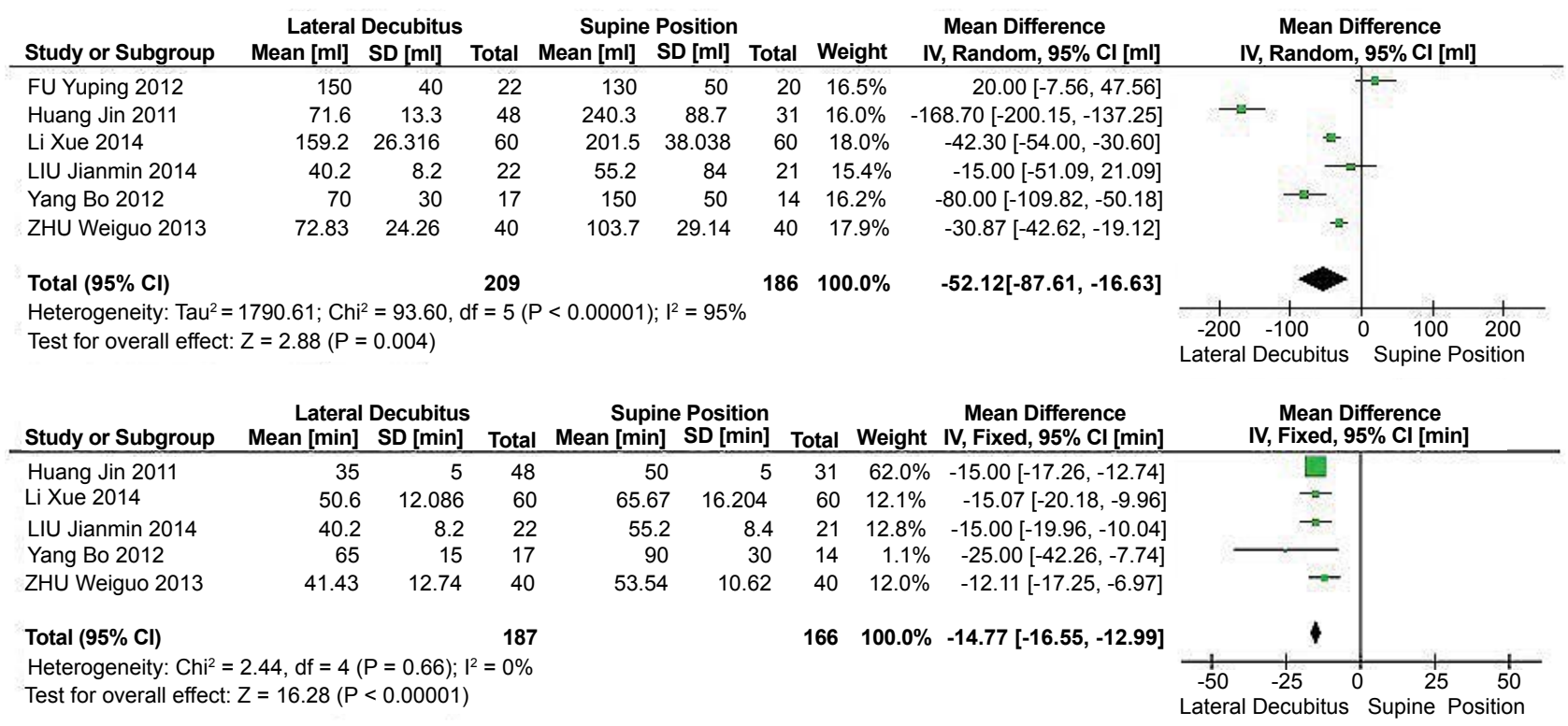

Figure 2: Forest plot of pooled WMD with $95 \% \mathrm{Cl}$ for comparing lateral decubitus with supine position for surgery for intertrochanteric fractures on the assessment of blood loss and operation time(The size of the data marker corresponds to the weight of the study. The diamond and vertical broken line represent the summary estimate).

It was showed in this meta-analysis that surgery in lateral decubitus was marginally associated with smaller incision compared with surgery in supine position $\left(\mathrm{WMD}_{\text {Length of incision }}=-2.47 \mathrm{~cm}, 95 \% \mathrm{CI}-2.64\right.$ to -2.30 , $\mathrm{P}<0.00001$ ) (Figure 3). Besides, sensitivity analysis by sequential omission of individual studies showed the significance of $\mathrm{WMD}_{\text {Length of }}$ incision was was robust, which suggested this outcome was credible.

\section{Harris values}

Data for Harris values were reported in 3 trials (Table 3 and Figure 4). There was no significant heterogeneity among these trials $\left(\mathrm{I}^{2}=0 \%, \mathrm{P}=0.83\right)$. The fixed effects model was used to pool the results. It was showed in this meta-analysis that surgery in lateral decubitus was marginally associated with higher score compared with surgery 
Citation: Liu F, Xie H, Liang W, Ye D, Yao Y (2016) A Meta-analysis Comparing Lateral Decubitus with Supine Position for Surgery for Intertrochanteric Fractures. J Arthritis 5: 211. doi: 10.4172/2167-7921.1000211

\begin{tabular}{|c|c|c|c|c|c|c|c|c|c|c|c|c|}
\hline \multirow{2}{*}{$\begin{array}{l}\text { Study or Subgroup } \\
\text { Li Xue } 2014\end{array}$} & \multicolumn{2}{|c|}{$\begin{array}{l}\text { Lateral Decubitus } \\
\text { Mean }[\mathrm{cm}] \text { SD }[\mathrm{cm}]\end{array}$} & Total & \multicolumn{2}{|c|}{ Supine Position } & Total & Weight & $\begin{array}{c}\text { Mean Difference } \\
\text { IV, Fixed, } 95 \% \mathrm{Cl}[\mathrm{cm}]\end{array}$ & \multicolumn{4}{|c|}{$\begin{array}{c}\text { Mean Difference } \\
\text { IV, Fixed, } 95 \% \mathrm{Cl}[\mathrm{cm}]\end{array}$} \\
\hline & 5.9 & 1.362 & 60 & 8 & 1.727 & 60 & $9.3 \%$ & $-2.10[-2.66,-1.54]$ & & - & & \\
\hline Yang Bo 2012 & 6 & 1 & 17 & 9 & 2 & 14 & $2.2 \%$ & $-3.00[-4.15,-1.85]$ & & - & & \\
\hline ZHU Weiguo 2013 & 4.2 & 0.5 & 40 & 6.7 & 0.3 & 40 & $88.5 \%$ & $-2.50[-2.68,-2.32]$ & & & & \\
\hline Total $(95 \% \mathrm{Cl})$ & & & 117 & & & 114 & $100.0 \%$ & $-2.47[-2.64,-2.30]$ & & 1 & & \\
\hline \multicolumn{4}{|c|}{ Heterogeneity: $\mathrm{Chi}^{2}=2.62, \mathrm{df}=2(\mathrm{P}=0.27) ; \mathrm{I}^{2}=24 \%$} & & & & & & $\begin{array}{l}+1 \\
-10 \\
\text { Late }\end{array}$ & $\begin{array}{c}1 \\
-5 \\
\text { I Decubitus }\end{array}$ & 0 & ion \\
\hline
\end{tabular}

Figure 3: Forest plot of pooled WMD with $95 \% \mathrm{Cl}$ for comparing lateral decubitus with supine position for surgery for intertrochanteric fractures on the assessment of length of incision (The size of the data marker corresponds to the weight of the study. The diamond and vertical broken line represent the summary estimate).

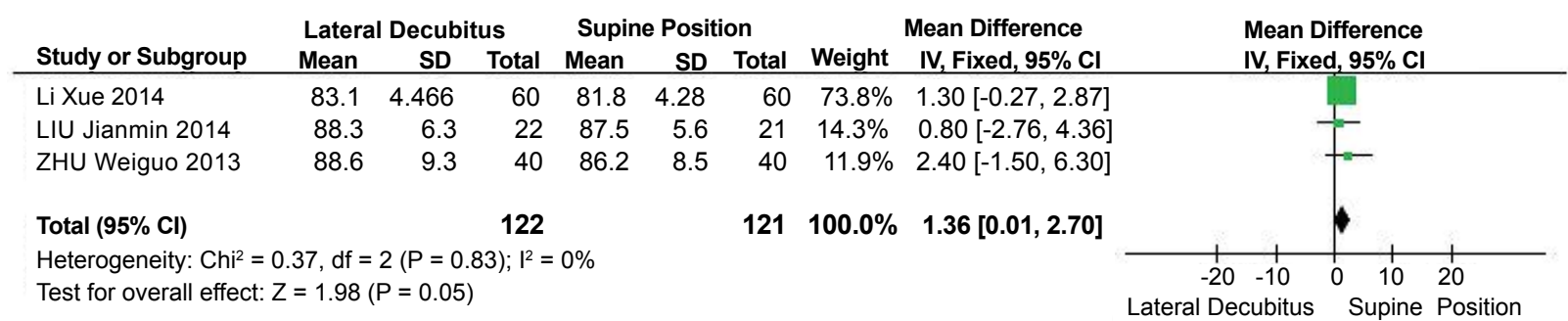

Figure 4: Forest plot of pooled WMD with $95 \% \mathrm{Cl}$ for comparing lateral decubitus with supine position for surgery for intertrochanteric fractures on the assessment of Harris values (The size of the data marker corresponds to the weight of the study. The diamond and vertical broken line represent the summary estimate).

\begin{tabular}{|c|c|c|c|c|c|c|c|c|}
\hline Study or Subgroup & $\begin{array}{r}\text { Lateral } \\
\text { Mean [days] }\end{array}$ & $\begin{array}{l}\text { Decubitus } \\
\text { SD [days] }\end{array}$ & Total & $\begin{array}{r}\text { Supine } \\
\text { Mean [days] }\end{array}$ & $\begin{array}{l}\text { e Position } \\
\text { SD [days] }\end{array}$ & Total & Weight & $\begin{array}{c}\text { Mean Difference } \\
\text { IV, Random, } 95 \% \text { CI [days] }\end{array}$ \\
\hline Huang Jin 2011 & 15.2 & 2.3 & 48 & 14.9 & 2.5 & 31 & $34.0 \%$ & $0.30[-0.79,1.39]$ \\
\hline Li Xue 2014 & 18 & 2.49 & 60 & 20.2 & 3.857 & 60 & $33.2 \%$ & $-2.20[-3.36,-1.04]$ \\
\hline LIU Jianmin 2014 & 15.3 & 2.6 & 22 & 16.1 & 1.2 & 21 & $32.7 \%$ & $-0.80[-2.00,0.40]$ \\
\hline Total $(95 \% \mathrm{Cl})$ & & & 130 & & & 112 & $100.0 \%$ & $-0.89[-2.34,0.55]$ \\
\hline
\end{tabular}

Heterogeneity: $\operatorname{Tau}^{2}=1.28 ; \mathrm{Chi}^{2}=9.44, \mathrm{df}=2(\mathrm{P}<0.009) ; \mathrm{I}^{2}=79 \%$

Test for overall effect: $Z=1.21(P=0.23)$

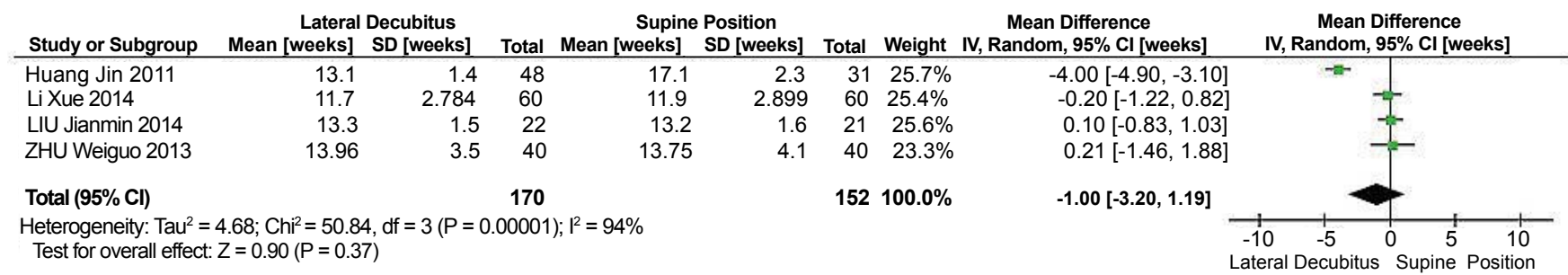

Figure 5: Forest plot of pooled WMD with $95 \% \mathrm{Cl}$ for comparing lateral decubitus with supine position for surgery for intertrochanteric fractures on the assessment of hospital stay and union time (The size of the data marker corresponds to the weight of the study. The diamond and vertical broken line represent the summary estimate).

in supine position $\left(\mathrm{WMD}_{\text {Harris values }}=1.36\right.$ points, $95 \% \mathrm{CI} 0.01$ to 2.70 , $\mathrm{P}=0.05$ ) (Figure 4). Besides, sensitivity analysis by sequential omission of individual studies showed the significance of $\mathrm{WMD}_{\text {Harris values }}$ was robust, which suggested this outcome was credible.

\section{Hospital stay and union time}

Data for hospital stay were reported in 3 trials (Table 3 and Figure 5). There was significant heterogeneity among these trials $\left(I^{2}=79 \%\right.$, $\mathrm{P}=0.009)$. The random effects model was used to pool the results. Metaanalysis showed that there was no different in term of the hospital stay between these two groups $\left(\mathrm{WMD}_{\text {Hospital stay }}=-0.89\right.$ days, $95 \% \mathrm{CI}-2.34$ to $-0.55, \mathrm{P}=0.23$ ) (Figure 5). Besides, sensitivity analysis by sequential omission of individual studies showed the significance of $\mathrm{WMD}_{\text {Hospital }}$ ${ }_{\text {stay }}$ was robust, which suggested this outcome was credible.
Data for union time were reported in 4 trials (Table 3 and Figure 5). There was significant heterogeneity among these trials $\left(I^{2}=94 \%\right.$, $\mathrm{P}<0.00001)$. The random effects model was used to pool the results. Meta-analysis showed that there was no different in term of the union time between these two groups $\left(\mathrm{WMD}_{\text {Union time }}=-1.00\right.$ weeks, $95 \% \mathrm{CI}$ -3.20 to $-1.19, \mathrm{P}=0.37$ ) (Figure 5). Besides, sensitivity analysis by sequential omission of individual studies showed the significance of $\mathrm{WMD}_{\text {Union time }}$ was robust, which suggested this outcome was credible.

\section{Discussion}

Proximal femoral nail antirotation is widely used in surgery for intertrochanteric fractures [2,3]. Surgeons can finish the surgery with PFNA either in lateral decubitus or in supine position. There are some studies comparing the outcomes of lateral dicubitus and supine 
position for surgery for intertrochanteric fractures, but there is obvious inconsistency of effects of those studies [14-21]. The better surgical position of surgery with PFNA remains controversial. Therefore, we performed this meta-analysis by including 6 randomized controlled trials to provide the most comprehensive assessment of lateral decubitus or supine position for surgery for intertrochanteric fractures. This metaanalysis showed the result that there were less blood loss $\left(\mathrm{WMD}_{\text {Blood }}\right.$ $=-52.12 \mathrm{ml}, 95 \% \mathrm{CI}-87.61$ to $-16.63, \mathrm{P}=0.004)$, less operation time $\left(\mathrm{WMD}_{\text {Operation time }}=-14.77 \mathrm{~min}, 95 \% \mathrm{CI}-16.55\right.$ to $\left.-12.99, \mathrm{P}<0.00001\right)$, smaller incision $\left(\mathrm{WMD}_{\text {Length of incision }}=-2.47 \mathrm{~cm}, 95 \% \mathrm{CI}-2.64\right.$ to -2.30 , $\mathrm{P}<0.00001)$ and higher Harris values score $\left(\mathrm{WMD}_{\text {Harris values }}=1.36\right.$ points, $95 \% \mathrm{CI} 0.01$ to $2.70, \mathrm{P}=0.05$ ) in lateral decubitus group. However, there was no difference in term of hospital stay $\left(\mathrm{WMD}_{\text {Hospital stay }}=-0.89\right.$ days, $95 \% \mathrm{CI}-2.34$ to $-0.55, \mathrm{P}=0.23)$ and union time $\left(\mathrm{WMD}_{\text {Union time }}=-1.00\right.$ weeks, $95 \% \mathrm{CI}-3.20$ to $-1.19, \mathrm{P}=0.37$ ) between those two groups.

The PFNA, which have been widely adopted for patients with intertrochanteric fractures, is an intramedullary device with a helical blade rather than a screw for better purchase in the femoral head [4$6,22,23]$. Surgery with PFNA in supine position has a high require of operating bed and equipment of fluoroscopy, which limits it being used in more primary hospitals. On the contrary, Surgery with PFNA in lateral decubitus doesn't need an extension table, so it can be performed in primary hospitals $[18,19]$. According to our meta-analysis, surgery with PFNA in lateral decubitus can benefit intertrochanteric fractures patients with less blood loss, less operation time, shorter incision and high Harris values scores. Thus, we should improve surgical technique with PFNA in lateral decubitus and generalize it to primary hospitals so that it can benefit more and more patients with intertrochanteric fractures.

Significant heterogeneity was observed between the included trials for intraoperative blood loss, hospital stay and union time. This heterogeneity may be attributable to variation in the skills of the surgeons and the different types of intertrochanteric fractures. The eligibility criteria for inclusion of intertrochanteric fractures patients were different from each other. The difference may have an influence on the obvious consistency of effects across those included studies and result in the heterogeneity. Besides, samples in trials included in this meta-analysis are not quite large, which may influence the heterogeneity. An individual patient data meta-analysis is necessary to ensure uniformity in either defining patients' characteristics for intertrochanteric fractures or defining outcome measures [24,25]. More randomized controlled trials with large samples are needed to decrease heterogeneity and make the outcome more meaningful.

In conclusion, surgery with PFNA in lateral decubitus can benefit intertrochanteric fractures patients with less blood loss, less operation time, shorter incision and high Harris values scores compared with surgery in supine position. In term of hospital stay and union time, there is no difference in these two surgical positions. However, more powered randomized studies are needed to identify the outcomes from this meta-analysis. Long-term period effects also need further studies.

\section{Compliance with Ethical Standards}

\section{Disclosure of potential conflicts of interest}

The authors declare that they have no conflict of interest.

\section{Research involving human participants and/or animals}

This article does not contain any studies with human participants or animals performed by any of the authors.

\section{Informed consent}

For this type of study formal consent is not required.

\section{Conflict of Interest}

The authors declare that they have no conflicts of interest concerning this article.

\section{References}

1. Pu JS, Liu L, Wang GL, Fang Y, Yang TF (2009) Results of the proximal femoral nail anti-rotation (PFNA) in elderly Chinese patients. Int Orthop 33: 1441-1444.

2. Bonnaire F, Zenker H, Lill C, Weber AT, Linke B (2005) Treatment strategies for proximal femur fractures in osteoporotic patients. Osteoporos Int 16 Suppl 2: S93-93S102.

3. Evans PJ, Mcgory BJ (2002) Fractures of the proximal femur- Hospital Physician.

4. Simmermacher RK, Ljungqvist J, Bail H, Hockertz T, Vochteloo AJ, et al. (2008) The new proximal femoral nail antirotation (PFNA) in daily practice: results of a multicentre clinical study. Injury 39: 932-939.

5. Mereddy P, Kamath S, Ramakrishnan M, Malik H, Donnachie N (2009) The AO/ ASIF proximal femoral nail antirotation (PFNA): a new design for the treatment of unstable proximal femoral fractures. Injury 40: 428-432.

6. Liu Y, Tao R, Liu F, Wang Y, Zhou Z, et al. (2010) Mid-term outcomes after intramedullary ?xation of peritrochanteric femoral fractures using the new proximal femoral nail antirotation (PFNA). Injury 41: 810-817.

7. Jadad AR, Moore RA, Carroll D, Jenkinson C, Reynolds DJ, et al. (1996) Assessing the quality of reports of randomized clinical trials: is blinding necessary? Control Clin Trials 17: 1-12.

8. Cochran WG (1954) The combination of estimates from different experiments International Biometric Society 10: 101-129.

9. Higgins JP, Thompson SG, Deeks JJ, Altman DG (2003) Measuring inconsistency in meta-analyses. BMJ 327: 557-560.

10. Mantel N, Haenszel W (1959) Statistical aspects of the analysis of data from retrospective studies of disease. J Natl Cancer Inst 22: 719-748.

11. DerSimonian R, Laird N (1986) Meta-analysis in clinical trials. Control Clin Trials 7: 177-188.

12. Tobias A (1999) Assessing the influence of a single study in the meta-analysis estimate. Stata Tech Bull 8: 15-17.

13. Stuck AE, Rubenstein LZ, Wieland D (1998) Bias in meta-analysis detected by a simple, graphical test. Asymmetry detected in funnel plot was probably due to true heterogeneity. BMJ 316: 469-471.

14. Xue L, Zha L, Chen Q, Liang YJ, Li KR, et al. (2013) Randomized Controlled Trials of Proximal Femoral Nail Antirotation in Lateral Decubitus and Supine Position on Treatment of Intertrochanteric Fractures. Scientific World Journal 2013: 276015

15. Weiguo Z, Yongqiang $H$ (2013) Effect observation of proximal femoral nail antirotation in different positions in the treatment of osteoporotic femoral intertrochanteric and subtrochanteric fracture in the elderly. China Medical Herald 10: 35

16. Jian-min L, Ya-jing Z, Jian-ming C, Gui-sheng Z (2014) Effect of Internal Fixation Using Proximal Femoral Nail Anti-rotation in Treatment of Obese Patients with Intertrochanteric Femoral Fracture in Different Postures. Medical \& Pharmaceutical Journal of Chinese People's Liberation Army 11: 52-55.

17. Yuping F, Jianling G, Xia L, Xuelian X (2012) Closed reduction and internal fixation with PFNA in different surgical position for intertrochanteric fractures in elderly. J Mod Med Health.

18. Jin H, Yang W, Xueli Q (2011) Comparing lateral decubitus with supine position for treatment with PFNA for intertrochanteric fractures. The Journal of Practical Medicine 27: 3914-3916.

19. Bo Y, Baoming S, Ping Z, Xiaozheng H (2012) Comparing two surgical position for treatment with PFNA for intertrochanteric fractures. Public Medical Forum Magazine 16: 13.

20. Qinyu L, Yishan H, Chunlei C, Weijun L, Dukai H, et al. (2012) A comparative study on applying two different positions in treating the elderly femora intertrochanteric fractures with PFNA. Orthopedic Journal of China. 
Citation: Liu F, Xie H, Liang W, Ye D, Yao Y (2016) A Meta-analysis Comparing Lateral Decubitus with Supine Position for Surgery for Intertrochanteric Fractures. J Arthritis 5: 211. doi: 10.4172/2167-7921.1000211

Page 6 of 6

21. Jianfei L, Jiaping C, Jie Z, Wei L, Jianming C (2014) The Clinical Efficacy of PFNA Internal Fixation in the Treatment for Femoral Intertrochanteric Fractures in the Two Position. Medical Innovation of China 11: 121-123

22. Sadic S, Custovic S, Jasarevic M, Fazlic M, Smajic N, et al. (2014) Proximal Femoral Nail Antirotation in Treatment of Fractures of Proximal Femur. Med Arch 68: 173-177.

23. Shen L, Zhang Y, Shen Y, Cui Z (2013) Antirotation proximal femoral nail versus dynamic hip screw for intertrochanteric fractures: A meta-analysis of randomized controlled studies. Orthop Traumatol Surg Res 99: 377-383.

24. Jiang SD, Jiang LS, Zhao CQ, Dai LY (2008) No advantages of Gamma nail over sliding hip screw in the management of peritrochanteric hip fractures: a meta-analysis of randomized controlled trials. Disabil Rehabil 30: 493-497.

25. Simmonds MC, Higgins JP, Stewart LA, Tierney JF, Clarke MJ, et al. (2005) Meta-analysis of individual patient data from randomized trials: a review of methods used in practice. Clin Trials 2: 209-217. 